\title{
Imagem Única de Destino: atributos exclusivos do destino Ilhéus, BA, Brasil
}

Lílian Dominguez Santanaa Marlusa de Sevilha Goslingb

\begin{abstract}
Resumo
Este estudo tem por objetivo desenvolver uma escala de mensuração da imagem única de um destino turístico a partir da percepção de profissionais diretamente ligados ao turismo local. 0 destino turístico pesquisado foi Ilhéus, principal cidade da zona turística Costa do Cacau no estado da Bahia, e realizou-se pesquisa de cunho qualitativo com 14 profissionais (professores universitários e profissionais ligados ao turismo de Ilhéus). A análise dos dados deu-se por análise de conteúdo, a partir da qual verificou-se a imagem única do destino principalmente relacionada a três aspectos: ambiente natural, atrativos e ambientação. Os resultados apontam que a singularidade do destino Ilhéus em relação a outros destinos semelhantes condiz com imagens comumente associadas ao destino (Jorge Amado, praias, cacau, chocolate); porém, também surgiram outros aspectos que representam oportunidades para promoção do destino. Por fim, os 14 atributos identificados compõem uma escala de mensuração da imagem única do destino Ilhéus que pode ser aplicada em estudos futuros relacionados a diferentes atores turísticos.
\end{abstract}

Palavras-chave: Imagem única de destino turístico; Ilhéus (BA); Jorge Amado; Cacau.

\section{Abstract \\ Unique image of a destination: exclusive attributes of the destination of Ilhéus, BA, Brazil}

This study aims to develop a scale of measurement of the unique image of a tourist destination based on the perception of workers directly related to local tourism. We researched the tourist destination of Ilhéus, the main city of the touristic zone of the Costa do Cacau (Cocoa Coast), in the state of Bahia. The qualitative research had 14 participants (university professors and workers related to the tourism industry in Ilheús). With content analysis, we verified that the unique image of the destination is mainly related to three aspects: natural environment, attractions and local environment. The results indicate that the uniqueness of the destination Ilhéus when compared with other similar destinations is compatible with the images that are commonly associated with the destination (Jorge Amado, beaches, cocoa, chocolate). However, other aspects that represent opportunities to promote the destination were also identified. Lastly, the 14 attributes determined compose a scale of measurement of the unique image of the destination Ilhéus, which could be applied to future studies related to different stakeholders from the tourism industry.

Keywords: Unique image of a tourist destination; Ilhéus (BA); Jorge Amado; Cocoa.

a. Mestre em Administração pela Universidade Federal de Minas Gerais (UFMG). Especialista em Marketing Estratégico (FTC). Belo Horizonte, Minas Gerais, Brasil. E-mail: liliandominguez@ufmg.br

b. Pós-doutorado em Gestão do Turismo pela Universidade do Algarve. Doutora em Administração pela UFMG. Professora Associada 2 de Marketing da UFMG e coordenadora do Núcleo de Estudos e Estratégias de Comunicação Integrada de Marketing e Turismo (Neecim-TUR). Belo Horizonte, Minas Gerais, Brasil. E-mail: marlusa@ufmg.br 


\section{Resumen}

Imagen única de destino: atributos únicos del destino Ilhéus, BA, Brasil

Este estudio tiene como objetivo desarrollar una escala de medición de la imagen única de un destino turístico desde la percepción de los profesionales directamente relacionados con el turismo local. El destino investigado fue Ilhéus, principal ciudad de la zona turística de la Costa del Cacao en el estado de Bahía, donde hemos llevado a cabo una investigación cualitativa con 14 profesionales (profesores universitarios y profesionales vinculados al turismo en Ilhéus). El análisis de datos ha sido llevada a cabo a través del análisis de contenido, desde el cual se verificó la imagen única del destino, relacionada principalmente con tres aspectos: entorno natural, atractivos y ambientación. Los resultados muestran que la singularidad de Ilhéus con respecto a otros destinos similares se condice con las imágenes comúnmente asociadas al destino: Jorge Amado, playas, cacao, chocolate. Sin embargo, surgieron también otros aspectos que representan oportunidades para promover el destino. Por fin, los 14 atributos identificados en esta investigación forman una escala de medición de la imagen única Ilhéus que se puede aplicar en futuros estudios con diferentes destinos turísticos.

Palabras clave: Imagen única del destino turístico; Ilhéus (BA); Jorge Amado; Cacao.

\section{INTRODUÇÃO}

Quando os consumidores estão diante de diferentes ofertas de serviço, precisam comparar e avaliar essas ofertas, percebendo para cada uma delas um valor diferente (LOVELOCK; WIRTZ; HEMZO, 2011). Nessa avaliação, segundo Lovelock, Wirtz e Hemzo (2011), os consumidores analisam três tipos de atributos: de busca (características tangíveis que permitem avaliar o produto antes da efetivação da compra); de credibilidade (características de difícil avaliação por parte dos clientes); e de experiência (atributos que não podem ser avaliados antes da compra). Nesse último encontram-se os produtos turísticos que, como ressaltado por Petrocchi (2004, p. 42), "não podem ser provados ou testados antecipadamente".

Conforme Qu, Kim e Im (2011), a singularidade de um destino é que fornece aos turistas razão imperativa para que o destino seja escolhido em detrimento das alternativas. Partindo dessa afirmação, os autores ressaltam como uma das dimensões da imagem de destino a imagem única ou imagem original. Justificam que, considerando as vastas opções de destinos turísticos com recursos semelhantes oferecidas aos consumidores, torna-se fundamental que o destino seja identificado como diferenciado e com características únicas nas mentes dos consumidores-alvo.

A partir dessas considerações, como identificar atributos únicos de um destino turístico? Para este estudo, tendo por objetivo identificar atributos únicos ou exclusivos de Ilhéus (BA) para compor uma escala de mensuração da imagem única do destino, foi realizada pesquisa qualitativa com profissionais ligados ao turismo de Ilhéus, visando obter descrições livres, o que, conforme Echtner e Ritchie (1991), consiste em uma metodologia propícia para capturar características únicas de imagem. Optou-se por realizar a pesquisa com público mais restrito e diretamente ligado ao turismo do destino tendo em vista a necessidade de maior conhecimento de sua história e características para o levantamento dos atributos únicos que o diferenciam. 
O destino Ilhéus, localizado no sul do estado da Bahia, foi escolhido por ser de particular interesse dos pesquisadores e por ser o principal destino da zona turística da Bahia denominada "Costa do Cacau". Os resultados da pesquisa não apenas contribuem para a identificação de atributos únicos do destino Ilhéus, que podem ser enfatizados em estratégias de promoção do destino, como também colaboram para a ampliação da discussão da dimensão única da imagem de destino.

\section{REVISÃO DE LITERATURA}

\section{Imagem de destino turístico: imagem única}

O que vem a ser uma imagem de destino? Tasci e Gartner (2007) explicam que uma imagem é uma construção mental desenvolvida pelo turista a partir de impressões ou pistas de informação. Imagem de destino turístico, portanto, trata-se de uma imagem mental que influencia o modo como a pessoa percebe o ambiente, o qual interfere no processo de tomada de decisão ao considerar as alternativas de destinos para suas experiências de turismo. Especialmente em serviços complexos, como são os destinos turísticos, a imagem torna-se crucial para a avaliação (CASTRO; MARTÍN ARMARIO; MARTÍN RUIZ, 2007).

Propondo um modelo teórico para o conceito de imagem de destino, Gallarza, Saura e García (2002) identificam quatro características dessa dimensão: natureza complexa, natureza múltipla, natureza relativística e natureza dinâmica. A natureza complexa está relacionada às concepções dos componentes que formam a imagem geral de um destino (cognitivo, cognitivo-afetivo) ou, mesmo, em relação à sua própria concepção: se decorre de uma impressão coletiva ou de impressões pessoais. A natureza múltipla diz respeito à multiplicidade de fatores ou variáveis que compõem uma imagem de destino - não há, efetivamente, consenso quanto à convicção de que uma imagem deve ser medida a partir de atributos ou a partir de uma visão holística ou geral. A natureza relativística, por sua vez, está relacionada ao envolvimento simultâneo de uma avaliação subjetiva, proveniente da interiorização de algumas percepções, e de uma avaliação comparativa em relação a vários objetos. Por fim, a imagem de destino apresenta uma natureza dinâmica, ou seja, não estática, em função, essencialmente, de dois fatores: o tempo e o espaço. Envolve desde a influência da localização geográfica dos indivíduos em relação ao destino até a visão processual (tempo) da formação da imagem (GALLARZA; SAURA; GARCÍA, 2002).

O modelo tridimensional proposto por Echtner e Ritchie (1991) permite a associação das dimensões propostas com pelo menos três ângulos dessas características da imagem de destino: as naturezas complexa, múltipla e relativística. 0 eixo funcional-psicológico pode ser relacionado à natureza complexa da imagem, que compreende que na avaliação da imagem de um destino contemplam-se desde elementos mais funcionais e racionais (cognitivos) até elementos mais abstratos (psicológicos) e emocionais (afetivos). 0 eixo atributo-holístico relaciona-se à natureza múltipla da imagem, que concebe que a imagem de um destino pode ser mensurada a partir da avaliação de atributos específicos ou de uma visão mais geral (holística). 0 eixo comum-único relaciona-se à natureza relativística da imagem, que entende que as características de um destino (sejam elas fun- 
cionais, psicológicas, específicas ou holísticas) podem ser analisadas em comparação a outros destinos, sendo denominadas "comuns" ou "de valor único". A natureza dinâmica poderia ser verificada, nesse contexto, a partir de um estudo longitudinal ou da comparação da imagem de um não visitante com a de um visitante, por exemplo.

A natureza complexa da imagem pode ser verificada no estudo de Baloglu e McCleary (1999), que propuseram um dos principais modelos de formação da imagem de destino que retrata a imagem global, ou geral, de um destino como aquela antecedida pela avaliação denominada "cognitiva", que consiste no conjunto de crenças e conhecimentos sobre o destino, e pela avaliação afetiva, que se refere aos sentimentos em relação a ele. A imagem global (positiva ou negativa) seria, portanto, uma combinação dos fatores cognitivos e afetivos (BEERLI; MARTÍN, 2004). Conforme San Martín e Rodríguez Del Bosque (2008), inicialmente apenas a dimensão cognitiva era considerada pelos estudos sobre imagem de destino (abordagem cognitiva tradicional). Posteriormente, a natureza cognitivo-afetiva foi proposta e considerada em diversas pesquisas posteriores.

Enquanto as avaliações, ou imagens, denominadas "cognitivas" e "afetivas" são amplamente reconhecidas pela literatura como dimensões da imagem de destino, mais uma dimensão foi incorporada por Qu, Kim e Im (2011). Os autores, baseando-se no conceito de imagem de marca, propuseram um modelo conceitual no qual acrescentaram à imagem cognitiva e à imagem afetiva a imagem única - no sentido de original, exclusiva ou singular - como formadora da imagem global de um destino. Isso corrobora com o modelo proposto por Echtner e Ritchie (1991).

Para Qu, Kim e Im (2011), associada ao conhecimento (imagem cognitiva) e ao sentimento (imagem afetiva), a percepção de singularidade (imagem única) é determinante para a formação da imagem global de um destino. Justificam que, tendo em vista as vastas opções de destinos turísticos oferecidas com recursos semelhantes, como acomodações de qualidade, bela vista e pessoas amigáveis, nada disso é suficiente para um destino se destacar. É fundamental que o destino seja identificado como diferenciado e com características únicas nas mentes dos consumidores-alvo. A singularidade do destino fornecerá a eles uma razão imperativa para que o destino seja escolhido em detrimento das alternativas.

Como a imagem única se refere a atributos únicos do destino, Qu, Kim e Im (2011) realizaram levantamento de estudos sobre a imagem do destino pesquisado em guias promocionais, a partir dos quais foram selecionados atributos que tornavam o destino original em relação a localidades vizinhas. Os autores esclarecem que, embora algumas dimensões para medir a imagem única e a imagem cognitiva sejam semelhantes, devem ser consideradas como distintas, porque enquanto a imagem cognitiva mede percepções de qualidade geral da experiência turística no destino, a imagem única tem foco na comparação do destino com destinos semelhantes. Segundo os autores, é possível que um atributo percebido como forte em imagem cognitiva seja menos forte quando comparado com outros destinos. Por exemplo, praia, sol e clima tropical podem ser elementos bem avaliados ao caracterizar determinado destino, mas não tão bem avaliados quando solicitado ao respondente que os compare a destinos semelhantes. 


\section{Destino Ilhéus: breve histórico e pesquisas anteriores}

Com 480 anos de fundação e 133 anos de emancipação política, Ilhéus é o principal destino da região turística Costa do Cacau, no sul do estado da Bahia. O município de Ilhéus apresenta população estimada de 178.210 pessoas (IBGE, 2016), uma área territorial de 1.584,693 km² (IBGE, 2015) e economia baseada principalmente em serviços (IBGE, 2013).

A história de Ilhéus inicia-se a partir do descobrimento do Brasil em 1500 e da divisão da colônia portuguesa em capitanias hereditárias pelo rei Dom João III. A Capitania de São Jorge dos Ilhéus, doada em 24 de abril de 1534 ao fidalgo português Jorge de Figueiredo Correia, foi elevada à categoria de vila em 1535 e chegou à condição de vila mais rica e próspera do país. Ilhéus tornou-se cidade em 28 de junho de 1881 a partir de um movimento na Assembleia Legislativa Provincial baiana (ILHÉUS, 2014a; 2014b; 2014c).

No mesmo período em que Ilhéus emancipou-se politicamente - no final do século XIX -, a lavoura cacaueira se expandiu e a região experimentou um período de grande prosperidade, e rapidamente a cultura do cacau se tornou a base econômica do sul da Bahia. A cidade, que apresentava infraestrutura primária com poucas ruas calçadas, casas rústicas, poucos sobrados, uma igreja matriz, um cemitério, uma cadeia e duas escolas primárias -, passou por grandes reestruturações (ILHÉUS, 2014b). Foi quando a iluminação pública a querosene chegou à cidade, milhares de trabalhadores rurais foram absorvidos pelas fazendas de cacau, que se multiplicavam velozmente, e diversos comerciantes de várias regiões do nordeste e do mundo foram atraídos, contribuindo para o aumento expressivo da população. No século XX a cidade foi remodelada com calçamento de ruas e praças e inaugurou-se a iluminação elétrica, o serviço de água encanada e o de esgoto. A estrada de ferro até Itabuna (BA), com cerca de $59 \mathrm{~km}$, e o Cine Teatro (casa de espetáculos) também foram inaugurados no período (MOREIRA, 2013b).

Com a construção do porto marítimo em 1920 (reformado em 1940 e inaugurado em 1970) e o fortalecimento das relações com a Europa, intensificaram-se as influências europeias sobre o comportamento da população local e a arquitetura, expressas pelas grandes mansões e prédios de estilo colonial e mesmo neogótico (como observado, por exemplo, no prédio do Instituto Nossa Senhora da Piedade). A grande riqueza levou os "coronéis" do cacau a investirem na modernização da cidade - com reformas, construções de igrejas e casarões -, contratando muitas vezes profissionais europeus exclusivamente para esse fim (NEVES, 2009). Eram resultados do progresso, como descrito por Jorge Amado na obra Gabriela, Cravo e Canela:

Progresso era a palavra que mais se ouvia em Ilhéus e em Itabuna naquele tempo. Estava em todas as bocas, insistentemente repetida. Aparecia nas colunas dos jornais, no quotidiano e nos semanários, surgia nas discussões na Papelaria Modelo, nos bares, nos cabarés. Os ilheenses repetiam-na a propósito das novas ruas, das praças ajardinadas, dos edifícios no centro comercial e das residências modernas na praia, das oficinas do Diário de Ilhéus, das marinetes saindo pela manhã e a tarde para Itabuna, dos caminhões transportando cacau, dos cabarés iluminados, do novo Cine-Teatro Ilhéus, do campo de futebol, do colégio do dr. Enoch, dos conferencistas esfomeados vindos da Bahia e até do Rio, do Clube Progresso com seus chás-dan- 
çantes. É o Progresso! Diziam-no orgulhosamente, conscientes de concorrerem todos para as mudanças tão profundas na fisionomia da cidade e nos seus hábitos. Havia um ar de prosperidade em toda parte, um vertiginoso crescimento. Abriam-se ruas para os lados do mar e dos morros, nasciam jardins e praças, construíam-se casas, sobrados, palacetes. (AMADO, 1975, p. 34-35)

Ilhéus, com o status de cidade próspera, tornou-se modelo de desenvolvimento regional e inspiração para a literatura. Por muitas décadas o cacau foi sinônimo de luxo, riqueza e prestígio para os moradores da região. A partir de 1980, porém, a lavoura cacaueira passou por uma crise sem precedentes (NEVES, 2009), decorrente, entre tantos outros fatores, da chegada do primeiro foco do fungo vulgarmente conhecido como "Vassoura de bruxa" (Moniliophtora perniciosa, anteriormente Crinipellis perniciosa), descoberto nas fazendas de cacau em 1989. A crise se instaurou levando à falência muitos produtores, à miséria grande parcela da população empregada nas fazendas de cacau, ao empobrecimento de toda a classe média e à estagnação econômica (MOREIRA, 2013b).

0 "Destino Ilhéus", no entanto, emergiu em meio a essa crise da lavoura cacaueira que atingiu o sul da Bahia. Com a literatura de Jorge Amado, Ilhéus passou de território comandado pelo cacau para outro marcado pelo turismo. De "Capital do Cacau" Ilhéus transformou-se em "Terra da Gabriela Cravo e Canela" ou "Terra de Jorge Amado". Com a crise, o foco voltou-se para o turismo, aproveitando a infraestrutura de Ilhéus, que, em função do cacau, já reunia espaço estruturado com aeroporto, porto, vias de acesso, saneamento básico e casarões do século XIX, além do potencial natural, com um litoral que compreende $100 \mathrm{~km}$ de praias (MOREIRA, 2013b). Importante destacar que o turismo em Ilhéus não surgiu apenas a partir da crise do cacau: o que houve foi uma ressignificação da atividade turística não somente em Ilhéus, mas em todo o Brasil (MOREIRA, 2013a).

Ilhéus guarda em sua história, cultura e arquitetura as impressões digitais da lavoura cacaueira. Diretamente ligados à época de ouro do cacau - e incluídos no circuito turístico de Ilhéus - estão a Igreja Matriz de São Jorge, a Catedral de São Sebastião (símbolo do centro histórico de Ilhéus), a Igreja de Santana em Rio do Engenho (uma das mais antigas do Brasil, tombada pelo Instituto do Patrimônio Histórico e Artístico Nacional), o conjunto arquitetônico do Instituto Nossa Senhora da Piedade, o prédio da Biblioteca Adonias Filho e a Casa dos Artistas. O Porto de Ilhéus, fortemente vinculado ao transporte do cacau, hoje recepciona diversos transatlânticos que aportam na cidade trazendo centenas de turistas. Como estratégia para aumentar a expectativa sobre o lugar e despertar o interesse na cultura local, a Secretaria Municipal de Turismo organiza estrutura com atores caracterizados dos personagens do romance de Jorge Amado, como Nacib e Gabriela, para receberem os turistas no Porto (MOREIRA, 2013b).

Datam da época do cacau também o Bar Vesúvio e o Bataclan, que serviram de cenário para o romance Gabriela, Cravo e Canela (AMADO, 1975). 0 Bar Vesúvio foi tombado pela Prefeitura de Ilhéus; o Bataclan, que funcionou como casa de prostituição, cabaré e cassino, fechado em 1950 em função da proibição dos jogos no Brasil, chegou a tornar-se boate, conjunto de apartamentos familiares e ruínas (quando abandonado). Foi reconstruído para fins de exploração turística entre 2000 e 2004, constituindo-se em um museu com a réplica do quarto de Maria Machadão (proprietária do lugar quando funcionava como cabaré e perso- 
nagem do romance de Jorge Amado), um café e uma loja de artesanatos regional. Em 2007 foi revitalizado, tornando-se Espaço Cultural Bataclan, onde se realizam projetos socioculturais, aulas de capoeira, exposições de arte, apresentações de teatro, bailes, saraus e lançamento de livros, mantendo a função de museu, café e bar, além de loja especializada em artigos de decoração (NEVES, 2009).

0 poder público foi fundamental para o desenvolvimento da cidade de Ilhéus e região para a promoção do turismo, inclusive na remodelação da cidade. Para facilitar o acesso aos prédios históricos, algumas ruas tiveram o trânsito de veículos impedido e foram transformadas em calçadões; outras ruas tiveram intervenções na estrutura básica e turística com inclusão de telefones públicos, quiosques de serviços e luminárias. 0 centro incluiu o adensamento de comércios e serviços, como restaurantes, bares, cinemas, agências de turismo e lojas de artesanato, localizados principalmente na avenida Soares Lopes, no centro da cidade à beira mar, endereço também do Centro de Convenções Luiz Eduardo Magalhães, que recebe shows, exposições, convenções e concertos.

A pavimentação de vias de acesso e de áreas em que se concentram casas de veraneio, resorts, hotéis, pousadas e condomínios de luxo também foi realizada. O Quarteirão Jorge Amado, dividido em dois circuitos - o circuito Cravo e o circuito Canela, em referência à obra de Jorge Amado -, foi uma iniciativa da Secretaria Municipal de Turismo e contempla prédios e monumentos referenciados nas obras do escritor (MOREIRA, 2013b).

Em pesquisa realizada no Portal de Periódicos Capes, utilizando como palavra-chave no título "Ilhéus", foram localizados 91 artigos e treze dissertações que se referem à cidade. Desses, catorze artigos e quatro dissertações tratavam de Ilhéus sob o aspecto do turismo, analisando: a hierarquia social ilheense e suas inter-relações com o turismo (PINTO, 2005); o turismo ali empreendido como um segmento de eventos e negócios (SCHIAVETTI et al., 2006) e como um segmento de turismo esportivo (BAHIA; ÁVILA, 2011); o impacto da tecnologia, literatura e mídia sobre o turismo ilheense (NASCIMENTO, 2006), bem como a forma como o destino é retratado a partir dos cartões postais comercializados (SOUZA, 2006); o modo como o turismo cultural, em termos de cultura negra, ocorre em Ilhéus (CAMPOS NEVES, 2008); e uma proposta de turismo cooperativo entre proprietários de Reservas Particulares do Patrimônio Natural (RPPN), órgãos públicos, cooperativas e instituições financeiras (SANTOS; PÁDUA; NEIMAN, 2013). As expectativas dos moradores da cidade em relação ao turismo também foram verificadas (NOIA; AVILA; MIDLEJ, 2009), assim como a exploração sexual infantil e o turismo sexual, tendo como objeto de estudo a atuação de um programa do Governo para o enfrentamento dessas questões em Ilhéus (SILVA; ÁVILA, 2010).

Porém, o tema mais tratado diz respeito à transformação pela qual Ilhéus passou desde os tempos da cultura e economia baseada no cacau até a sua consolidação como destino turístico. Foram analisadas a transição de "Capital do Cacau" para a "Terra de Jorge Amado" ou "Terra da Gabriela, Cravo e Canela" (MOREIRA, 2013b) e a construção do patrimônio histórico-cultural (NEVES, 2009) e do espaço urbano (MOREIRA, 2013a) da cidade de Ilhéus. Os fatores determinantes da oferta turística do município de Ilhéus em alta estação (CERQUEIRA; FREIRE, 2010) e em baixa estação (CERQUEIRA, 2002) foram identificados, mas apenas um artigo localizado buscou identificar especificamente a imagem turística do destino Ilhéus (SANTOS; CRUZ, 2013). 
Esses três últimos estudos fornecem uma avaliação do destino Ilhéus sob o ponto de vista do visitante em dois momentos distintos: alta e baixa estação. Desconsiderando as diferenças no design das pesquisas, de forma geral, pode-se analisar os resultados dos estudos como uma perspectiva do Destino Ilhéus nos anos de 2002, 2007 e 2013 (quando as respectivas pesquisas foram realizadas); trata-se de um período de mais de dez anos, em que se constatou que os atrativos naturais do destino são seu principal ponto forte. Entretanto, durante esse período permanece a deficiência quanto aos serviços públicos (com ênfase para a segurança pública, limpeza e sinalizações) e às alternativas de entretenimento e diversão - principalmente à noite -, além das debilidades ou falta das manifestações populares esperadas.

\section{METODOLOGIA}

Para se atingir o objetivo de descobrir atributos percebidos por profissionais direta ou indiretamente ligados ao turismo como exclusivos e únicos de Ilhéus, procedeu-se a uma investigação de cunho qualitativo. A pesquisa foi feita a partir de formulário online ${ }^{1}$ com perguntas abertas.

Esta pesquisa visa o desenvolvimento de uma escala de imagem única do destino Ilhéus e, por esta razão, por juízo e opção dos pesquisadores, decidiu-se por buscar as visões de stakeholders influentes. Foram escolhidos, como amostra inicial, profissionais ligados à educação, turismo e informação com o objetivo de obter uma visão mais crítica e realista sobre o destino, uma vez que esses profissionais o vivenciam e discutem sobre ele. Foram convidados 59 participantes, sendo 26 professores da Universidade Estadual de Santa Cruz (Uesc), cinco professores da Faculdade de Tecnologia e Ciências e da União Metropolitana de Educação e Cultura, oito alunos do Curso de Geografia da Uesc, editores do Boletim Informe Geográfico $^{2}$, cinco profissionais que atuam na Secretaria de Turismo de Ilhéus, catorze profissionais ligados ao ramo hoteleiro da cidade e um profissional executivo da TV Santa Cruz.

O convite foi feito através de correspondência eletrônica com link para o formulário, explicando a pesquisa e solicitando o compartilhamento da pesquisa com outros profissionais que estivessem ligados ao turismo de Ilhéus (acadêmica ou profissionalmente), intencionando a ampliação da amostragem a partir da rede de contato desses profissionais. A coleta das informações, no entanto, foi delimitada considerando a saturação teórica - ponto em que se percebe que as respostas dos participantes passam a ser repetidas, sem acrescentar novos elementos à pesquisa (FONTANELLA et al., 2011). A pesquisa, portanto, foi fechada com catorze participantes. A demonstração do ponto de saturação verificado na pesquisa pode ser conferida no Quadro 1.

0 roteiro teve por base questões utilizadas por Machado (2010) em sua pesquisa e dividiu-se em duas seções principais. A primeira seção foi montada com questões abertas e com questões para completar frases relacionadas ao destino. A primeira questão apresentou campo livre para a manifes-

1. Disponível em: <https://goo.gl/forms/oecP38Wruh7WJS0a2>.

2. Disponível em: <http://informegeografico.blogspot.com.br/>. 
tação do participante da pesquisa em relação àquilo que considerava único/ exclusivo de Ilhéus como destino turístico. Essa questão foi seguida por uma questão contrária, também em campo aberto, que se referia àquilo que outros destinos do litoral do nordeste têm e que falta em Ilhéus; o objetivo principal dessa pergunta foi o de possibilitar a exclusão de atributos, levantados por outros participantes, já sinalizados como deficientes. Em seguida, quatro questões para completar foram incluídas, de modo a fornecer uma orientação para as respostas, e incluíram: "Ilhéus é uma cidade...", "Em Ilhéus o turista encontra...", "Ilhéus é um destino caracterizado principalmente por..., “Os turistas devem visitar Ilhéus porque...”. Finalizando essa primeira seção, uma pergunta foi incluída visando extrair possíveis elementos mais abstratos relacionados à ambientação do destino, na qual foi solicitado ao respondente que informasse como descreveria o destino Ilhéus se ele fosse um turista.

A segunda seção apresentou imagens comumente relacionadas aos atrativos do destino e aos temas associados pelos órgãos de promoção (Figura 1): "Capital do Cacau", "Terra de Jorge Amado", "Terra da Gabriela, Cravo e Canela", "Paraíso do Chocolate" (VIVER BAHIA, 2011). Essa seção foi separada da seção inicial em página sequencial, de modo a não influenciar as respostas livres. Foi solicitado ao respondente que informasse qual das imagens representava melhor o destino Ilhéus. Em seguida, foi solicitado que as imagens fossem colocadas em ordem de representatividade do destino e que fosse descrito se essas imagens representavam características únicas/exclusivas do destino.

Figura 1 - Imagens relacionadas aos atrativos do destino utilizadas na pesquisa

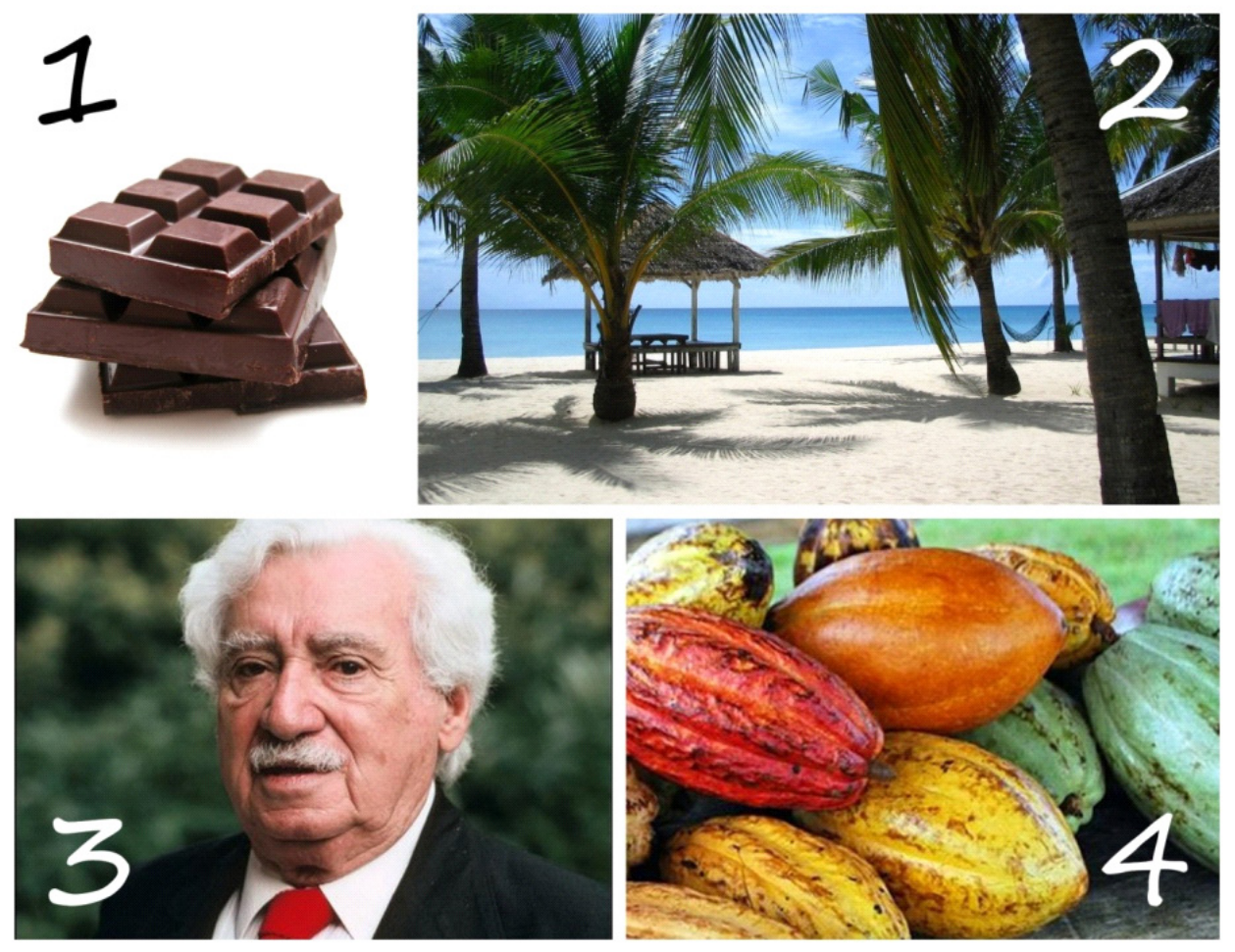

Fonte - Elaborada pelas autoras 
Os dados qualitativos foram analisados a partir do método de análise de conteúdo pela abordagem acumulativa, na qual inicia-se com contagem de frequência de palavras e parte-se para a análise do conteúdo latente (ROSSI; SERRALVO; JOÃO, 2014). Conforme Bardin (1994, p. 42), a análise de conteúdo é um "conjunto de técnicas de análise das comunicações, que utiliza procedimentos sistemáticos e objetivos de descrição do conteúdo das mensagens". Segundo a autora, uma análise de conteúdo envolve três fases: a pré-análise dos dados, a exploração do material e o tratamento dos resultados, inferência e interpretação (BARDIN, 1994).

No caso desta pesquisa, a etapa da pré-análise dos dados incluiu a exportação das respostas fornecidas em questionário online e leitura prévia das observações levantadas. A transcrição dos formulários não foi necessária em função do instrumento utilizado (Google Forms), que permitiu acesso direto às respostas. A exploração do material e o tratamento dos resultados envolveu a verificação da frequência de frases com indicações de características únicas do destino Ilhéus e a categorização dessas frases em grupos com significados ou conotações semelhantes. Por fim, a partir dessas categorias, os indicadores da imagem única do destino foram extraídos. Em função do pequeno número de participantes e de perguntas, não foi necessário utilizar software específico; a codificação foi feita em planilha do Excel e a contagem de frequência foi realizada com o auxílio de tabelas dinâmicas.

\section{RESULTADOS E DISCUSSÃo}

Com base nas etapas sugeridas por Bardin (1994), após a leitura prévia das respostas fornecidas foi realizada codificação a partir de temas ou afirmações feitas pelos entrevistados acerca do destino Ilhéus. Tomando por base cada afirmação, foram extraídos atributos e um quadro foi elaborado para a compilação e remoção de atributos duplicados. 0 Quadro 1 apresenta o levantamento desses atributos, sinalizando (em itálico) as duplicações verificadas e o ponto de saturação das respostas a partir das observações do último respondente.

Quadro 1 - Atributos únicos do destino Ilhéus identificados na pesquisa qualitativa

\begin{tabular}{|c|c|}
\hline RESPONDENTE 1 & RESPONDENTE 2 \\
\hline $\begin{array}{l}\text { Destaca-se por ser um destino que associa } \\
\text { natureza e cultura }\end{array}$ & $\begin{array}{l}\text { Um dos destaques de Ilhéus são suas praias de } \\
\text { areia branca e fina }\end{array}$ \\
\hline É uma cidade atrativa & Destaca-se pela beleza da cidade \\
\hline Destaca-se por sua história & Destaca-se por suas belas paisagens \\
\hline É um destino divertido/brincalhão & Destaca-se pelo clima exuberante \\
\hline É um destino sensual & Destaca-se pelas belas praias \\
\hline Destaca-se pelas belas praias & Um dos destaques é a vasta natureza \\
\hline $\begin{array}{l}\text { Destaca-se pela riqueza das obras de } \\
\text { Jorge Amado }\end{array}$ & Um dos destaques é a extensão do seu litoral \\
\hline \multirow[t]{4}{*}{ Um dos destaques é a cacauicultura } & Destaca-se por ser um destino misterioso \\
\hline & Destaca-se por ser um destino charmoso \\
\hline & $\begin{array}{l}\text { Um dos destaques é a imponência e beleza do } \\
\text { seu patrimônio histórico e cultural }\end{array}$ \\
\hline & Destaca-se pela riqueza das obras de Jorge Amado \\
\hline
\end{tabular}

(continua...) 


\section{Quadro 1 - Continuação}

\begin{tabular}{|c|c|}
\hline RESPONDENTE 3 & RESPONDENTE 4 \\
\hline Destaca-se por suas belezas naturais & Um dos destaques é a cacauicultura \\
\hline Destaca-se por sua história & Destaca-se pelas belas praias \\
\hline Destaca-se por sua cultura & Destaca-se por suas belas paisagens \\
\hline $\begin{array}{l}\text { Um dos destaques é estar situado em área de } \\
\text { Mata Atlântica preservada }\end{array}$ & Destaca-se por sua história \\
\hline Um dos destaques é a cacauicultura & Destaca-se por sua cultura \\
\hline Um dos destaques é a rica literatura histórica & Destaca-se por ser um destino agradável \\
\hline Destaca-se pela beleza da cidade & Destaca-se pela beleza da cidade \\
\hline Um dos destaques é o calor humano & $\begin{array}{l}\text { Um dos destaques é o seu patrimônio histórico } \\
\text { e cultural }\end{array}$ \\
\hline Destaca-se pelas belas praias & Ilhéus é um destino rústico \\
\hline \multicolumn{2}{|l|}{ Destaca-se por ser um destino tranquilo } \\
\hline \multicolumn{2}{|l|}{$\begin{array}{l}\text { Destaca-se por seu patrimônio histórico e } \\
\text { cultural }\end{array}$} \\
\hline \multicolumn{2}{|l|}{$\begin{array}{l}\text { Destaca-se pela riqueza das obras de } \\
\text { Jorge Amado }\end{array}$} \\
\hline \multicolumn{2}{|l|}{ Destaca-se por suas belas paisagens } \\
\hline \multicolumn{2}{|l|}{ É um destino rústico } \\
\hline RESPONDENTE 5 & RESPONDENTE 6 \\
\hline $\begin{array}{l}\text { Destaca-se pela cultura espacialmente ligada } \\
\text { às obras de Jorge Amado }\end{array}$ & Destaca-se por suas belezas naturais \\
\hline Destaca-se por sua cultura & Destaca-se por sua beleza geográfica \\
\hline Destaca-se pela beleza da cidade & Destaca-se pelas belas praias \\
\hline Destaca-se pelas belas praias & Um dos destaques são as festas \\
\hline $\begin{array}{l}\text { A gastronomia também é um destaque de } \\
\text { Ilhéus }\end{array}$ & Destaca-se por sua cultura \\
\hline Um dos destaques é a cacauicultura & A gastronomia também é um destaque de Ilhéus \\
\hline \multirow[t]{5}{*}{ O chocolate também é um destaque de Ilhéus } & Destaca-se por ser um destino aconchegante \\
\hline & Destaca-se por ser um destino relaxante \\
\hline & É um destino sensual \\
\hline & O chocolate também é um destaque de Ilhéus \\
\hline & $\begin{array}{l}\text { Destaca-se pela riqueza das obras de } \\
\text { Jorge Amado }\end{array}$ \\
\hline RESPONDENTE 7 & RESPONDENTE 8 \\
\hline $\begin{array}{l}\text { Destaca-se pela ambientação da riqueza das } \\
\text { obras de Jorge Amado }\end{array}$ & Destaca-se por suas belezas naturais \\
\hline Destaca-se por suas belezas naturais & Destaca-se por sua rica história \\
\hline Destaca-se por sua cultura & Destaca-se por sua cultura \\
\hline $\begin{array}{l}\text { Destaca-se por apresentar um clima estável } \\
\text { todo o ano. }\end{array}$ & $\begin{array}{l}\text { Destaca-se devido à sua importância para a } \\
\text { economia brasileira nos tempos do cacau }\end{array}$ \\
\hline Destaca-se por sua rica história & Destaca-se pela beleza da cidade \\
\hline Destaca-se pelas belas praias & Destaca-se pelas belas praias \\
\hline $\begin{array}{l}\text { Destaca-se por sua rica cultura material e } \\
\text { imaterial }\end{array}$ & Destaca-se por apresentar um clima agradável \\
\hline
\end{tabular}




\section{Quadro 1 - Continuação}

\section{RESPONDENTE 7}

Um dos destaques de Ilhéus é estar situado em área de Mata Atlântica preservada

Destaca-se por suas belas paisagens

\section{É um destino rústico}

RESPONDENTE 9

Destaca-se por sua riqueza natural: sol, praia, rio, Mata Atlântica

O chocolate também é um destaque de Ilhéus

Destaca-se pela beleza da cidade

É um destino sensual

Um dos destaques de Ilhéus é a cacauicultura

0 cacau é um dos destaques da gastronomia de Ilhéus

\begin{tabular}{|c|c|}
\hline & Destaca-se pela beleza da cidade \\
\hline & É um destino sensual \\
\hline & É um destino naturalmente belo \\
\hline & $\begin{array}{l}\text { Destaca-se pela riqueza das obras de } \\
\text { Jorge Amado }\end{array}$ \\
\hline & Um dos destaques é a cacauicultura \\
\hline & É um destino que une fantasia e natureza \\
\hline & É um destino rústico \\
\hline RESPONDENTE 11 & RESPONDENTE 12 \\
\hline $\begin{array}{l}\text { Destaca-se pela ambientação da riqueza das } \\
\text { obras de Jorge Amado }\end{array}$ & $\begin{array}{l}\text { Um dos destaques são as fazendas da época } \\
\text { áurea do cacau }\end{array}$ \\
\hline Um dos destaques é o fácil acesso às praias & $\begin{array}{l}\text { Destaca-se pela sua riqueza histórica } \\
\text { relacionada ao cacau e aos coronéis }\end{array}$ \\
\hline $\begin{array}{l}\text { Um dos destaques são as fazendas da época } \\
\text { áurea do cacau }\end{array}$ & Destaca-se pelas belas praias \\
\hline $\begin{array}{l}\text { Um dos destaques são os diferentes estilos } \\
\text { arquitetônicos }\end{array}$ & Destaca-se por suas belezas naturais \\
\hline Um dos destaques são os casarões históricos & $\begin{array}{l}\text { Destaca-se por ser uma cidade que faz parte da } \\
\text { história do país }\end{array}$ \\
\hline \multirow[t]{3}{*}{ Um dos destaques é a cacauicultura } & É um destino maduro \\
\hline & $\begin{array}{l}\text { Destaca-se pela riqueza das obras de } \\
\text { Jorge Amado }\end{array}$ \\
\hline & Um dos destaques é a cacauicultura \\
\hline RESPONDENTE 13 & RESPONDENTE 14 \\
\hline $\begin{array}{l}\text { Destaca-se pelo patrimônio arquitetônico } \\
\text { exclusivo advindo da época áurea do cacau e } \\
\text { dos coronéis }\end{array}$ & $\begin{array}{l}\text { Destaca-se pela ambientação da riqueza das } \\
\text { obras de Jorge Amado }\end{array}$ \\
\hline Destaca-se por suas belas paisagens & Destaca-se por suas belezas naturais \\
\hline Destaca-se pela beleza da cidade & $\begin{array}{l}\text { Destaca-se por ser um destino que associa } \\
\text { natureza e cultura }\end{array}$ \\
\hline Destaca-se por sua história & Destaca-se pela beleza da cidade \\
\hline Destaca-se pelas belas praias & Destaca-se pelas belas praias \\
\hline
\end{tabular}

(continua...)

\section{RESPONDENTE 8}

Destaca-se pela riqueza histórica do cacau

Destaca-se por ser cenário das obras de Jorge Amado

\section{RESPONDENTE 10}

Destaca-se por sua rica história

Destaca-se por suas belezas naturais

Um dos destaques é a rica literatura histórica

É um destino mágico

É um destino cheio de surpresas

Destaca-se pelas belas praias

Destaca-se pela beleza da cidade

É um destino sensual

Destaca-se pela riqueza das obras de

Jorge Amado

Um dos destaques é a cacauicultura

É um destino que une fantasia e natureza

RESPONDENTE 12

áurea do cacau

Destaca-se pela sua riqueza histórica relacionada ao cacau e aos coronéis

Destaca-se pelas belas praias

estaca-se pelas belas praias 
Quadro 1 - Continuação

\begin{tabular}{|l|l|}
\hline RESPONDENTE 13 & RESPONDENTE 14 \\
\hline É um destino maduro & $\begin{array}{l}\text { Destaca-se por apresentar um clima estável } \\
\text { todo o ano. }\end{array}$ \\
\hline $\begin{array}{l}\text { Um dos destaques é a cacauicultura } \\
\text { Destaca-se pela riqueza das obras de } \\
\text { Jorge Amado }\end{array}$ & Um dos destaques é a cacauicultura \\
\hline
\end{tabular}

Fonte - Dados da pesquisa

Essas afirmações foram categorizadas conforme uma temática comum, incluindo: cacau, ambientação, praias, Jorge Amado, cidade, natureza, cultura, história, gastronomia, paisagens, clima, história e cultura, mata atlântica, arquitetura, natureza e cultura, festas e fantasia e natureza.

A abordagem quantitativa (frequência) foi adotada para a interpretação dos dados e elaboração final dos indicadores, assim como para a identificação dos atributos mais citados pelos entrevistados como atrativos únicos do destino a partir das categorias. A análise da frequência dos indicadores pode ser conferida no Quadro 2, a partir do qual é também possível perceber os atributos mais citados: "Ilhéus destaca-se pelas belas praias", "Um dos destaques de Ilhéus é a cacauicultura", "Ilhéus destaca-se pela beleza da cidade" e "Ilhéus destaca-se pela riqueza das obras de Jorge Amado".

Quadro 2 - Atributos únicos do destino Ilhéus: análise de frequência

\begin{tabular}{|l|c|}
\hline Indicadores por categoria & $\begin{array}{c}\text { No de vezes } \\
\text { que foram }\end{array}$ \\
\hline identificados \\
\hline CACAU & $\mathbf{1 6}$ \\
\hline Um dos destaques de Ilhéus é a cacauicultura & 10 \\
\hline Um dos destaques de Ilhéus são as fazendas da época áurea do cacau & 2 \\
\hline Patrimônio arquitetônico exclusivo advindo da época áurea do cacau e dos & 1 \\
\hline coronéis & \\
\hline Riqueza histórica do cacau & 1 \\
\hline Importância para a economia brasileira nos tempos do cacau & 1 \\
\hline Riqueza histórica relacionada ao cacau e aos coronéis & 1 \\
\hline AMBIENTAÇÃo & 20 \\
\hline É um destino sensual & 4 \\
\hline É um destino rústico & 4 \\
\hline É um destino maduro & 2 \\
\hline É um destino cheio de surpresas & 1 \\
\hline Um dos destaques é o calor humano & 1 \\
\hline É um destino charmoso & 1 \\
\hline É um destino divertido/brincalhão & 1 \\
\hline É um destino misterioso & 1 \\
\hline É um destino agradável & 1 \\
\hline
\end{tabular}


Quadro 2 - Continuação

\begin{tabular}{|c|c|}
\hline Indicadores por categoria & $\begin{array}{c}\text { № de vezes } \\
\text { que foram } \\
\text { identificados }\end{array}$ \\
\hline É um destino aconchegante & 1 \\
\hline É um destino tranquilo & 1 \\
\hline PRAIAS & 15 \\
\hline Destaca-se pelas belas praias & 12 \\
\hline Fácil acesso às praias & 1 \\
\hline Praias de areia branca e fina & 1 \\
\hline A extensão do seu litoral & 1 \\
\hline JORGE AMADO & 12 \\
\hline Riqueza das obras de Jorge Amado & 7 \\
\hline Ambientação da riqueza das obras de Jorge Amado & 3 \\
\hline Cenário para as obras de Jorge Amado & 1 \\
\hline Cultura espacialmente ligada às obras de Jorge Amado & 1 \\
\hline CIDADE & 10 \\
\hline A beleza da cidade & 9 \\
\hline É uma cidade atrativa & 1 \\
\hline NATUREZA & 10 \\
\hline Destaca-se por suas belezas naturais & 7 \\
\hline Um dos destaques é a vasta natureza & 1 \\
\hline É um destino naturalmente belo & 1 \\
\hline Beleza geográfica & 1 \\
\hline CULTURA & 9 \\
\hline Destaca-se por sua cultura & 6 \\
\hline Um dos destaques é a rica literatura histórica & 2 \\
\hline Rica cultura material e imaterial & 1 \\
\hline HISTÓRIA & 8 \\
\hline Destaca-se por sua história & 4 \\
\hline Destaca-se por sua rica história & 3 \\
\hline Destaca-se por ser uma cidade que faz parte da história do país & 1 \\
\hline GASTRONOMIA & 6 \\
\hline O chocolate também é um destaque de Ilhéus & 3 \\
\hline A gastronomia também é um destaque de Ilhéus & 2 \\
\hline O cacau é um dos destaques da gastronomia de Ilhéus & 1 \\
\hline PAISAGENS & 5 \\
\hline Destaca-se por suas belas paisagens & 5 \\
\hline CLIMA & 4 \\
\hline Clima estável todo o ano & 2 \\
\hline Clima exuberante & 1 \\
\hline Destaca-se por apresentar um clima agradável & 1 \\
\hline HISTÓRIA E CULTURA & 3 \\
\hline Destaca-se por seu patrimônio histórico e cultural & 1 \\
\hline
\end{tabular}


Quadro 2 - Continuação

\begin{tabular}{|l|c|}
\hline Indicadores por categoria & $\begin{array}{c}\text { No de vezes } \\
\text { que foram } \\
\text { identificados }\end{array}$ \\
\hline Patrimônio histórico e cultural & 1 \\
\hline A imponência e beleza do seu patrimônio histórico e cultural & 1 \\
\hline MATA ATLÂNTICA & $\mathbf{3}$ \\
\hline Localização em área de Mata Atlântica preservada & 2 \\
\hline Destaca-se por sua riqueza natural: sol, praia, rio, Mata Atlântica & 1 \\
\hline ARQUITETURA & 2 \\
\hline Os diferentes estilos arquitetônicos & 1 \\
\hline Os casarões históricos & 1 \\
\hline NATUREZA E CULTURA & 2 \\
\hline Destaca-se por ser um destino que associa natureza e cultura & 2 \\
\hline FESTAS & $\mathbf{1}$ \\
\hline Um dos destaques são as festas & 1 \\
\hline FANTASIA E NATUREZA & $\mathbf{1}$ \\
\hline É um destino que une fantasia e natureza & 1 \\
\hline Total geral & $\mathbf{1 2 7}$ \\
\hline
\end{tabular}

Esses atributos estão diretamente relacionados às imagens mais frequentemente associadas ao destino Ilhéus: cacau, praias, Jorge Amado e chocolate. Essas imagens fizeram parte também do formulário de pesquisa, no qual foi solicitado aos participantes que colocassem as imagens em ordem de representatividade do destino Ilhéus. 0 resultado pode ser conferido na Tabela 1.

Tabela 1 - Representatividade das imagens sobre o destino Ilhéus

\begin{tabular}{|c|c|c|c|c|c|}
\hline $\begin{array}{c}\text { Ordem de } \\
\text { representatividade }\end{array}$ & Chocolate & Praias & $\begin{array}{c}\text { Jorge } \\
\text { Amado }\end{array}$ & Cacau & $\begin{array}{c}\text { Total de } \\
\text { participantes }\end{array}$ \\
\hline 1 & 0 & $\mathbf{6}$ & 4 & 4 & 14 \\
\hline 2 & 1 & 5 & $\mathbf{7}$ & 1 & 14 \\
\hline 3 & 3 & 2 & 2 & 7 & 14 \\
\hline 4 & $\mathbf{1 0}$ & 1 & 1 & 2 & 14 \\
\hline
\end{tabular}

Fonte - Dados da pesquisa

Ocupam o primeiro lugar em termos de representatividade de Ilhéus as praias, citadas por $43 \%$ dos entrevistados. Em segundo lugar, a figura e a obra do escritor Jorge Amado, citadas por 50\% dos participantes. Em terceiro lugar, aparece o cacau, citado também por $50 \%$ dos respondentes, e em último, o chocolate, citado por $71 \%$. Porém, essa configuração não é um consenso. Há posições bem marcantes enfatizando cada uma das três primeiras (praias, Jorge Amado e cacau) como sendo a mais representativa. As duas últimas foram citadas por $29 \%$ dos participantes como sendo as primeiras colocadas. Defendendo a posição da 
primeira colocada, os participantes enfatizam: "Hoje em dia [o destino é escolhido] mais pelas praias, mas o Jorge Amado ajudou muito nesse processo. As praias de areia branca e fina. Já estive em outras praias pelo Brasil, e essa é uma característica ímpar" (RESPONDENTE 2).

0 cacau é também muito citado como elemento mais representativo do destino:

A cultura cacaueira é o diferencial de Ilhéus, proporcionando experiências peculiares com o modo de produção, além de histórias memoráveis. [...] Apenas o cacau, cujo histórico e modo peculiar de produção é bastante rico e diferente das mais diversas culturas agrícolas do Brasil. A imagem de Jorge Amado está bem melhor explorada por Salvador. A cidade não possui tradição chocolateira. E praias, a própria Bahia tem mais de mil quilômetros semelhantes. (RESPONDENTE 4)

A figura de Jorge Amado e suas obras, no entanto, talvez tenham sido as mais enfaticamente defendidas como imagem única do destino:

No contexto regional (microrregião Ilhéus-Itabuna, composta por 41 municípios), em relação aos destinos turísticos praianos (litorâneos), Ilhéus se destaca não tanto pelos seus aspectos da natureza ou patrimônio arquitetônico, mas sim pela representação simbólica que possui por conta da figura simbólica de Jorge Amado e sua literatura, a qual divulgou a cidade Brasil afora. [...] Ilhéus, diferente de Itabuna, possui aspectos importantes para o turismo, como diversas praias, arquitetura histórica no espaço urbano associada ao período áureo da cacauicultura, igrejas de diferentes estilos arquitetônicos, praças etc. Além disso, existe no espaço rural algumas fazendas da época áurea do cacau. No entanto, esses são elementos que outras cidades da região possuem também, em suas especificidades. No que se refere ao que Ilhéus tem de único/exclusivo, se comparado a outras localidades, vejo, conforme já mencionado, a projeção nacional e internacional do nome da cidade com seus cenários e seus personagens retratados nas histórias de Jorge Amado, o que a projeta como um verdadeiro simulacro (uma imagem retratada além da realidade, espetacularizada na mente de quem a imagina e a quer consumir como um produto turístico), conforme visão de simulacro desenvolvida pelo francês Jean Baudrillard. Portanto, Ilhéus é mais consumida turisticamente pela imagem criada sobre ela do que realmente pelo que ela tem. (RESPONDENTE 11)

Apesar de ter sido sinalizado em último lugar como imagem representativa do destino, órgãos de fomento do turismo na Bahia, como a Secretaria de Turismo, têm enfatizado o chocolate como destaque de Ilhéus, denominando-a "Paraíso do chocolate" (VIVER BAHIA, 2011). É possível, portanto, conciliar essas posições quanto à imagem representativa de Ilhéus, conforme destacado pelo respondente 9: "Poderia ser uma mistura das quatro. Nessa terra você encontra um pouco de todas elas" (RESPONDENTE 9).

Como alerta Bauer (2008), muitas vezes a análise de conteúdo a partir da abordagem quantitativa considera apenas os dados frequentes, descuidando do que é raro. Desse modo, a abordagem quantitativa não foi a única a ser utilizada. Concordando com Bardin (1994, p. 115-116) "o que caracteriza a análise qualitativa é o fato de a inferência [...] ser fundada na presença do índice [...] e não sobre a frequência de sua aparição". Não somente as afirmações frequentes acerca do destino foram consideradas para os indicadores. 
Para elaborar atributos mais abstratos relacionados à ambientação, partiu-se da questão da caracterização do destino Ilhéus como uma pessoa, e dessa pergunta surgiram elementos interessantes, como "sensualidade do destino". Esse indicador foi extraído de afirmações como "Brejeira" (que diz respeito a próprio de garoto, malicioso, gaiato, brincalhão, apimentado, picante), sinalizado pelo RESPONDENTE 1, “Gostosa” (RESPONDENTE 6), "Uma mulher morena alta, linda e cheia de mistérios" (RESPONDENTE 2).

Considerando, portanto, tanto a análise quantitativa quanto a qualitativa dos dados, identificou-se como atributos exclusivos do destino Ilhéus:

- Ambiente natural:

- Clima estável todo o ano.

- Localização em área de mata atlântica preservada.

- Grande extensão do litoral.

- Praias de areia branca e fina.

- Beleza geográfica.

- Atrativos locais (culturais):

- Chocolate local.

- Cozinha local saborosa.

- Cacauicultura.

- Patrimônio cultural, histórico e arquitetônico advindo da época áurea do cacau e dos coronéis.

- Ambientação da riqueza das obras de Jorge Amado.

- Ambientação:

- Sensualidade do destino.

- Ambiente charmoso.

- Ambiente rústico.

- Calor humano.

Constituindo a imagem única do destino Ilhéus, tem-se, portanto, 14 indicadores agrupados em 3 dimensões: ambiente natural, atrativos locais e ambientação.

\section{CONSIDERAÇÕES FINAIS}

Tendo por objetivo a identificação dos atributos únicos ou singulares do destino Ilhéus (BA) para a construção de uma escala de mensuração para a sua imagem única, foi realizada pesquisa qualitativa com profissionais ligados ao turismo local. A partir da análise de conteúdo dos dados coletados foi possível extrair 14 indicadores da imagem única de Ilhéus relacionados ao ambiente natural, atrativos e ambientação local. A análise dos atributos que surgiram na pesquisa permite a identificação de atributos funcionais, mas também, e predominantemente, de atributos mais abstratos não apenas referentes à ambientação do local, mas principalmente relacionados à riqueza histórica e literária que formam o imaginário e as expectativas em relação ao destino. 
Muitos atributos estão relacionados às imagens comumente associadas ao destino, como a cacauicultura, patrimônio cultural, histórico e arquitetônico, obras de Jorge Amado, praias de areia branca e fina. Porém, há que se observar outros atributos ressaltados nos resultados que podem representar oportunidades no que tange à atratividade do destino, como a localização em área de mata atlântica, a extensão do litoral, a beleza geográfica, a cozinha, o calor humano, o ambiente rústico e o clima estável todo o ano.

Os atributos identificados compõem uma escala da imagem única do destino Ilhéus, a partir da qual é possível mensurar a percepção de singularidade do destino. Como sugestão para estudos futuros cita-se a aplicação da escala de imagem única do destino resultante desta pesquisa em um estudo mais amplo, com públicos diferentes ligados ao destino (moradores, comerciantes, empresários, poder público) e com turistas para verificar se esses atributos são efetivamente percebidos como únicos. Além disso, sugere-se testar empírica e quantitativamente a escala de imagem única, composta pelas três dimensões aqui identificadas, já que, pela própria limitação do método aqui empregado, não se pode generalizar o resultado encontrado. 0 teste quantitativo, então, com uma amostra adequada e probabilística, possibilitaria estender o achado.

\section{REFERÊNCIAS}

AMADO, J. Gabriela, cravo e canela. 51. ed. São Paulo: Record; Martins, 1975.

BAHIA, C. S.; ÁVILA, M. A. Sports Events and Tourism Development in Ilhéus - Bahia Brazil. Estudios y Perspectivas en Turismo, Buenos Aires, v. 20, n. 1, p. 171-189, 2011.

BALOGLU, S.; MCCLEARY, K. W. A model of destination image formation. Annals of Tourism Research, Amsterdam, v. 26, n. 4, p. 868-897, 1999.

BARDIN, L. Análise de conteúdo. Lisboa: Edições 70, 1994.

BAUER, M. W. Análise de conteúdo clássica: uma revisão. In: BAUER, M. W e GASKELL, G. Pesquisa qualitativa com texto, imagem e som: um manual prático. 7. ed. Petrópolis: Vozes, 2008. p. 189-219.

BEERLI, A.; MARTÍN, J. D. Factors influencing destination image. Annals of Tourism Research, Amsterdam, v. 31, n. 3, p. 657-681, 2004.

CAMPOS NEVES, S. Black culture and tourism in Ilhéus, Brazil: tourist publicity, cultural contact and clichés. Estudios y Perspectivas en Turismo, Buenos Aires, v. 17, n. 4, p. 319338, 2008.

CASTRO, C. B.; MARTÍN ARMARIO, E.; MARTÍN RUIZ, D. The influence of market heterogeneity on the relationship between a destination's image and tourists' future behaviour. Tourism Management, London, v. 28, n. 1, p. 175-187, 2007.

CERQUEIRA, C. A. de. Análise estrutural do turismo do município de Ilhéus (BA). 2002. 167 p. Dissertação (Mestrado em Ciências) - Escola Superior de Agricultura Luiz de Queiroz, Universidade de São Paulo, Piracicaba, 2002.

CERQUEIRA, C. A.; FREIRE, C. R. F. Fatores determinantes da oferta turística do município de Ilhéus (Bahia) na alta estação do ano de 2007. Revista Turismo em Análise, São Paulo, v. 21, n. 1, p. 47-67, 2010.

ECHTNER, C. M.; RITCHIE, J. B. The meaning and measurement of destination image. Journal of Tourism Studies, [s. l.], v. 2, n. 2, p. 2-12, 1991. 
FONTANELLA, B. J. B. et al. Amostragem em pesquisas qualitativas: proposta de procedimentos para constatar saturação teórica. Caderno de Saúde Pública, Rio de Janeiro, v. 27, n. 2, p. 389-394, 2011.

GALLARZA, M. G.; SAURA, I. G.; GARCÍA, H. C. Destination image: towards a conceptual framework. Annals of Tourism Research, Amsterdam, v. 29, n. 1, p. 56-78, 2002.

IBGE - INSTITUTO BRASILEIRO DE GEOGRAFIA E ESTATÍSTICA. Cidades: Ilhéus. 2015. Disponível em: <http://bit.ly/2mEIFza>. Acesso em: 13 dez. 2016.

. Histórico: Ilhéus. 2014. Disponível em: <http://cod.ibge.gov.br/po8>. Acesso em: 23 mar. 2017.

. Produto Interno Bruto dos municípios: Ilhéus. 2013. Disponível em: <http://bit. ly/2mEIFza>. Acesso em: 13 dez. 2016.

. Resolução no 4, de 29 de agosto de 2016. Divulga as estimativas da população para estados e municípios. Diário Oficial da União, Brasília, DF, 30 ago. 2016. Seção 1, p. 47-65.

ILHÉUS. A capitania torna-se cidade em 1881. 2014a. Disponível em: <http://bit.ly/2n0bIOr>. Acesso em: 1 dez. 2014.

. História completa de Ilhéus. 2014c. Disponível em: <http://bit.ly/2mCSbRT>. Acesso em: 1 dez. 2014.

LOVELOCK, C.; WIRTZ, J.; HEMZO, M. A. Marketing de serviços: pessoas, tecnologia e estratégia. 7. ed. São Paulo: Pearson, 2011.

MACHADO, D. F. C. A imagem do destino turístico, na percepção dos atores do trade turístico: um estudo da cidade histórica de Diamantina/MG. 2010. Dissertação (Mestrado em Administração) - Universidade Federal de Minas Gerais, Belo Horizonte, 2010.

MOREIRA, G. L. A reprodução do espaço urbano da cidade de Ilhéus: turismo, segregação e mercantilização do espaço. Revista da Casa da Geografia de Sobral, Sobral, v. 15, n. 1, p. 32-48, 2013a.

. Ilhéus, a terra da Gabriela cravo e canela: de espaço do cacau a espaço do turismo. GeoTextos, Salvador, v. 9, n. 1, p. 129-150, 2013b.

NASCIMENTO, A. S. de B. Tecnologia, literatura e mídia para a sustentabilidade turística ilheense. Perspectivas Contemporâneas, Campo Mourão, v. 1, n. 2, p. 39-53, 2006.

NEVES, K. F. T. V. De cabaré a espaço cultural: um olhar geográfico sobre o patrimônio histórico de Ilhéus-BA a partir do estudo do caso Bataclan. GeoTextos, Salvador, v. 5, n. 1, p. 113-141, 2009.

NOIA, A. C.; AVILA, M. A.; MIDLEJ, M. B. C. Desarrollo turístico y comunidad local: valoraciones y expectativas de los residentes de Ilhéus-BA, Brasil. Estudios y Perspectivas en Turismo, Buenos Aires, v. 18, n. 6, p. 634-654, 2009.

PETROCCHI, M. Marketing para destinos turísticos. São Paulo: Futura, 2004.

PINTO, R. Dos frutos de ouro às hordas douradas: turismo, grupos de status e estilos de vida em Ilhéus, Brasil. PASOS, Revista de Turismo y Patrimonio Cultural, Santa Cruz de Tenerife, v. 3, n. 1, p. 189-197, 2005.

QU, H.; KIM, L. H.; IM, H. H. A model of destination branding: integrating the concepts of the branding and destination image. Tourism Management, London, v. 32, n. 3, p. 465-476, 2011.

ROSSI, G. B.; SERRALVO, F. A.; JOÃO, B. N. Content Analysis. Revista Brasileira de Marketing, São Paulo, v. 13, n. 4, p. 39-48, 2014.

SAN MARTÍN, H.; RODRÍGUEZ DEL BOSQUE, I. A. Exploring the cognitive-affective nature of destination image and the role of psychological factors in its formation. Tourism Management, London, v. 29, n. 2, p. 263-277, 2008. 
SANTOS, E. de S.; CRUZ, G. da. Imagen turística de Ilhéus (BA-Brasil): según la percepción de los visitantes. Estudios y Perspectivas en Turismo, Buenos Aires, v. 22, n. 4, p. 607-629, 2013.

SANTOS, M. C. de M.; PÁDUA, S. M.; NEIMAN, Z. Desafios e potencialidades para a implantação do turismo cooperativo como ferramenta de viabilização das RPPNs de Ilhéus (BA, Brasil). PASOS, Revista de Turismo y Patrimonio Cultural, Santa Cruz de Tenerife, v. 11, n. 4, p. 671-685, 2013.

SCHIAVETTI, A. et al. Turismo de eventos y negocios: el caso del Ilhéus y Costa del Cacao Convention \& Visitors Bureau, Brasil. Estudios y Perspectivas en Turismo, Buenos Aires, v. 15, n. 1, p. 67-80, 2006.

SILVA, T. A.; ÁVILA, M. A. Turismo sexual e exploração sexual infantil: uma análise da atuação do programa sentinela em Ilhéus. PASOS, Revista de Turismo y Patrimonio Cultural, Santa Cruz de Tenerife, v. 8, n. 1, p. 185-193, 2010.

SOUZA, F. de P. Reflexões a partir dos cartões-postais de Ilhéus - Bahia/Brasil. Revista Internacional Interdisciplinar INTERthesis, Florianópolis, v. 3, n. 2, p. 1-18, 2006.

TASCI, A. D. A.; GARTNER, W. C. Destination image and its functional relationships. Journal of Travel Research, [s. l.], v. 45, n. 4, p. 413-425, 2007.

VIVER BAHIA. Salvador: Secretaria do Turismo do Estado da Bahia, v. 5, n. 16, 2011. Edição Especial. Disponível em: <http://bit.ly/2n26WQL>. Acesso em: 1 dez. 2015.

Recebido em: 26/06/2016

Aprovado em: 09/02/2017 